\title{
DETECTION OF VOIDS IN KARST TERRAIN WITH FULL WAVEFORM TOMOGRAPHY
}

\author{
Khiem T. Tran \\ Assistant Professor, Clarkson University, Department of Civil and Environmental Engineering, 8 Clarkson Ave., \\ P.O. Box 5710, Potsdam, NY13699-5710,USA, ktran@clarkson.edu
}

\author{
Michael McVay \\ Professor, University of Florida, Department of Civil and Coastal Engineering, 365 Weil Hall, P.O. Box 116580, \\ Gainesville, FL, 32611,USA, mom@ce.ufl.edu
}

\section{Trung Dung Nguyen}

Ph.D. student, Clarkson University, Department of Civil and Environmental Engineering, 8 Clarkson Ave., P.O. Box 5710, Potsdam, NY 13699-5710, USA, nguyent@clarkson.edu

\begin{abstract}
This paper presents an application of time-domain surfacebased waveform tomography for detection of voids in karst terrain. The measured seismic surface wave fields were inverted using a full waveform inversion (FWI) technique, based on a finite-difference solution of 2-D elastic wave equations and the Gauss-Newton inversion method. The FWI was applied to real experimental data sets collected from twelve test lines at a karst site in Florida. Two of the test lines were located next to open karst chimneys to image their extent. Ten other test lines were located in an open and flat area without any void indication from the ground surface to detect an unknown void. The inversion results show that the waveform analysis was able to delineate embedded low-velocity anomalies, a void, and highly variable bedrock both laterally and vertically. Locations of the low-velocity anomalies were consistent to the known open chimneys observed from the ground surface. The unknown identified void was confirmed by an independent standard penetration test (SPT).
\end{abstract}

\section{Introduction}

Embedded void detection in a site usually begins with non-destructive testing (NDT), as NDT data can provide general subsurface conditions over a large volume of materials. At suspicious locations (anomalies), more involved invasive methods such as the Cone Penetration Test (CPT) or Standard Penetration Test (SPT) are then conducted to obtain more detailed information. Various approaches have been developed and employed to characterize voids, ranging from gravity, resistivity, ground-penetrating radar and traditional seismic wave methods. These methods have both advantages and limitations in identifying and quantifying voids.
As reviewed by Plessix (2008) and Vireux and Operto (2009), the full waveform inversion (FWI) approach offers the potential to produce higher resolution images of the subsurface by extracting information contained in the complete waveforms rather than approaches using only the dispersive properties of Rayleigh waves or firstarrival signals. Nasseri-Moghaddama et al. (2007), for example, have clearly shown that the recorded responses at the surface can carry valuable information regarding the presence and characterization of anomalies, e.g., voids, below the surface. However, FWI is computationally intensive, requiring a full solution of the governing wave equation. Many algorithms for waveform inversion have been developed and applied to synthetic and real seismic data in large-scale (kilometer-scale) domains (Shipp and Singh, 2002; Ravaut et al., 2004; Sheen et al., 2006; Cheong et al. 2006; Brenders and Pratt, 2007; Choi and Alkhalifah, 2011; and others). In larger scale experiments surface waves can clearly separate from body waves and be removed in the inversion process. However, at shorter length scales (meter-scale), it is difficult to separate body waves from surface waves, and only a few studies of waveform inversion involving both body and surface waves have been performed for near-surface investigations on synthetic data (Ge'lis et al., 2007; Romdhane et al., 2011) or real experimental laboratory data (Bretaudeau et al., 2013).

A 2-D full waveform inversion (2-D FWI) technique (Tran and McVay, 2012) was reported which inverted both body and surface waves in the case of real experimental data. The technique includes forward modeling to generate synthetic wavefields and employs the GaussNewton inversion method to update model parameters 
until the residual between predicted and measured surface velocities are negligible. For the forward modeling, the classic velocity-stress staggered-grid finite difference solution of 2-D elastic wave equations in the time domain (Virieux, 1986) are used in combination with perfectly matched layer boundary conditions (Kamatitsch and Martin, 2007). For model updating, the Gauss-Newton method involves minimizing the residual between the estimated responses obtained by forward simulation and the observed seismic data. Virtual sources and a reciprocity principle are used to calculate partial derivative wavefields (via the gradient matrix) to reduce computational time. Observed and estimated wavefields are convolved with appropriate reference traces to remove the influence of source signatures. The inversion technique is independent of sources, or source signatures are not required to be measured during field testing. Any source signatures (e.g., sine, triangle, or Ricker wavelets) having the same central frequency of the measured data can be used for inversion. See Tran and McVay, 2012, for details.

In this article the FWI is utilized for detection of embedded voids/anomalies in karst terrain. The inversion was carried out independently for $\mathrm{P}$ - and $\mathrm{S}$-wave velocities in each cell with the mass density of the medium assumed constant.

\section{Application}

The 2-D FWI scheme was applied to a real test site to investigate the capability of the FWI in characterizing highly variable subsurface profiles and embedded anomalies. The test site was a Florida Department of Transportation (FDOT) retention pond located in Newberry, Florida. From invasive tests, the site consisted of medium dense, fine sand and silt 2 to $5 \mathrm{~m}$ thick, overlying a highly variable limestone deposit; the top of limestone varied from $2 \mathrm{~m}$ to $10 \mathrm{~m}$ in depth (Tran and Hiltunen, 2011). The site was divided into 26 parallel north-south survey lines equally spaced $3.0 \mathrm{~m}$ apart. The lines were labeled $\mathrm{A}$ through $\mathrm{Z}$ from west to east across the site, and each line was about $200 \mathrm{~m}$ long, with station $0 \mathrm{~m}$ located at the southern end of each line. Twelve test lines were conducted at southern and northern portions of the site.

\section{Southern Portion of the Site}

Two test lines were conducted next to open chimneys in the unconsolidated sediments (Figure 1) at the southern portion of the site. The chimneys were formed due to sinkhole activities. Line 1 was at the grid line G6-G42, next to open chimneys 1 and 2. Line 2 was at the grid line $28 \mathrm{~A}-28 \mathrm{~K}$, perpendicular to line 1 , and next to open chimneys 2 and 3. Due to safety concerns, the two test lines were conducted about $1 \mathrm{~m}$ away from the chimneys.

Line 1 (G6-G42) was conducted using a linear array of $244.5-\mathrm{Hz}$ vertical geophones at a spacing of $1.5 \mathrm{~m}$, for a total receiver spread of $34.5 \mathrm{~m}$ (station $0.75 \mathrm{~m}$ to $35.25 \mathrm{~m}$ ). The seismic energy was created by striking a $150-\mathrm{mm}$ square metal plate with a $90 \mathrm{~N}$ sledgehammer. Twenty-five shots at $1.5 \mathrm{~m}$ spacing were recorded, for a total shot spread of $36.0 \mathrm{~m}$ (station $0.0 \mathrm{~m}$ to 36.0 $\mathrm{m})$. Line $2(28 \mathrm{~A}-28 \mathrm{~K})$ was conducted using the same 24 geophones at a spacing of $1.2 \mathrm{~m}$ for a total receiver spread of $27.6 \mathrm{~m}$ (station $0.6 \mathrm{~m}$ to $28.2 \mathrm{~m}$ ). Twenty-five shots at $1.2-\mathrm{m}$ spacing were recorded for a total shot spread of $28.8 \mathrm{~m}$ (station $0.0 \mathrm{~m}$ to $28.8 \mathrm{~m}$ ). Unlike line 1 , the geophone spacing of $1.2 \mathrm{~m}$ (instead of $1.5 \mathrm{~m}$ ) was used in an attempt to characterize smaller chimneys.

For line 1 data analysis, a proper initial model is required to avoid the inversion being trapped in local minima. For simplicity, an estimate of the initial model was established via a spectral analysis of the measured data. A linear increasing S-wave velocity from $200 \mathrm{~m} / \mathrm{s}$ at the surface to $400 \mathrm{~m} / \mathrm{s}$ to a depth of $18 \mathrm{~m}$ (half of test line length) over a length of $36 \mathrm{~m}$ was considered. The initial P-wave velocity for the domain was calculated from the S-wave velocities assuming that the initial Poisson's ratio throughout the domain was 0.25 . The mass density throughout the model was kept constant at $1,800 \mathrm{~kg} / \mathrm{m}^{3}$ for all inversions. Three inversion runs were performed for frequency ranges with central frequencies of 10,15 , and $20 \mathrm{~Hz}$, beginning from the lowest frequency range. The medium of $18 \mathrm{~m} \times 36$ $\mathrm{m}$ was divided into about 1200 cells of $0.75 \mathrm{~m} \times 0.75$ $\mathrm{m}$. During the inversion, S-wave and P-wave velocities of cells were updated independently, and each run was stopped after 20 iterations when the observed waveform data and the estimated waveform data were similar.

The final results are shown in Figure 2A for analysis of the data at $20 \mathrm{~Hz}$. Locations of chimneys 1 and 2 are also shown in Figure 2A for comparison. The final inverted S-wave profile (Figure 2A, top) shows two low-velocity zones at distances $12 \mathrm{~m}$ and $21 \mathrm{~m}$, along with high lateral and vertical variations in limestone boundaries (Vs $>800$ $\mathrm{m} / \mathrm{s}$ ) at the bottom of profile. Evidently these anomaly 

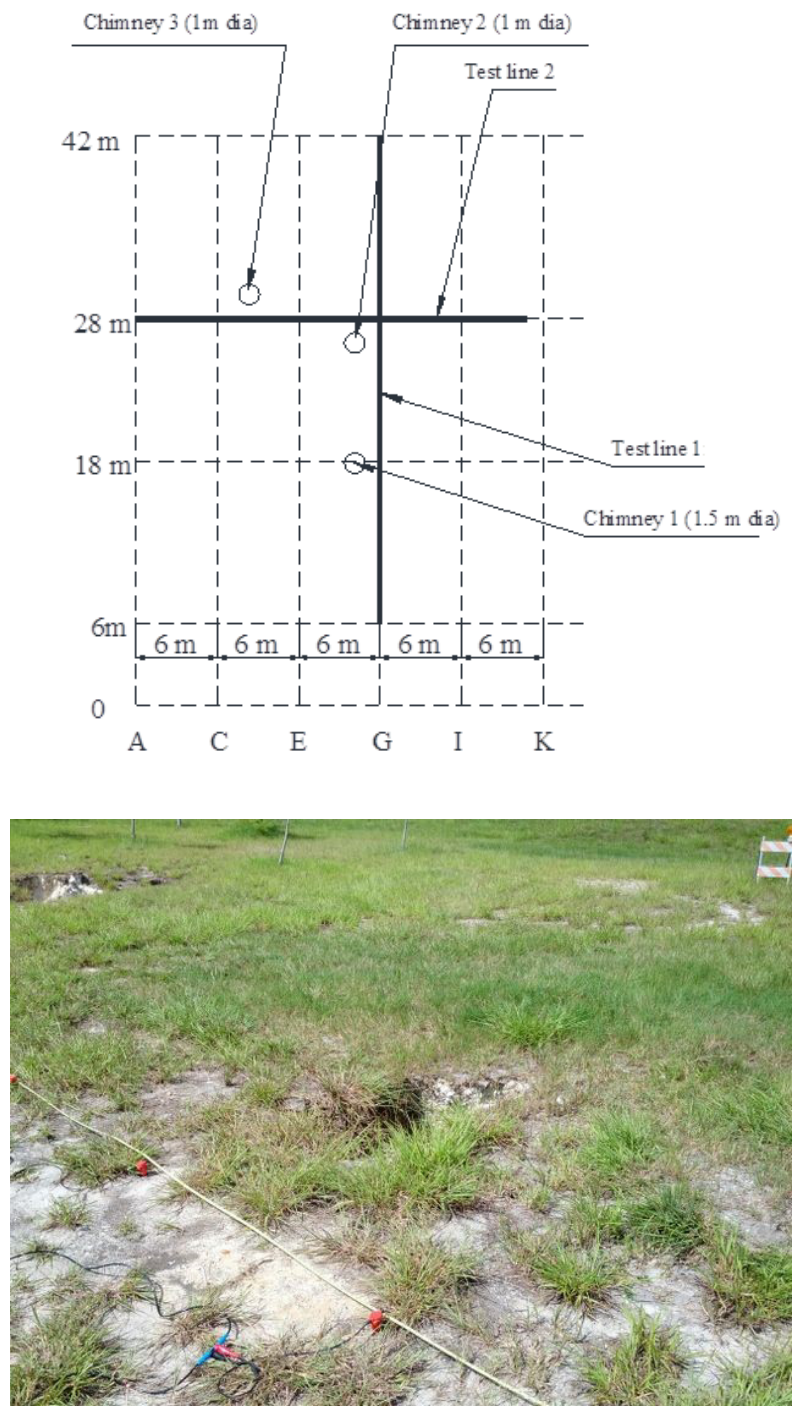

locations were the same as those of the chimneys (i.e., $12 \mathrm{~m}$ and $21 \mathrm{~m}$ ). Note that the exact depths of chimneys were not measured due to safety concerns.

The inverted P-wave profile (Figure 2A, bottom) was consistent with the estimated S-wave profile. Chimney 1 of about $1.5 \mathrm{~m}$ diameter was also characterized in both S-wave and P-wave images. Chimney 2 of about 1-m diameter was not shown, due to 3-D effects. To characterize the smaller chimney, the test line may have needed to be closer to the chimney, and data at higher frequencies $(20-40 \mathrm{~Hz})$ may also have been required.

Data analysis for line 2 was similar to that of line 1 . The medium of $14.4 \mathrm{~m} \times 28.4 \mathrm{~m}$ was divided into about 1200 cells of $0.6 \mathrm{~m} \times 0.6 \mathrm{~m}$. Three inversion runs were performed for frequency ranges with central frequencies
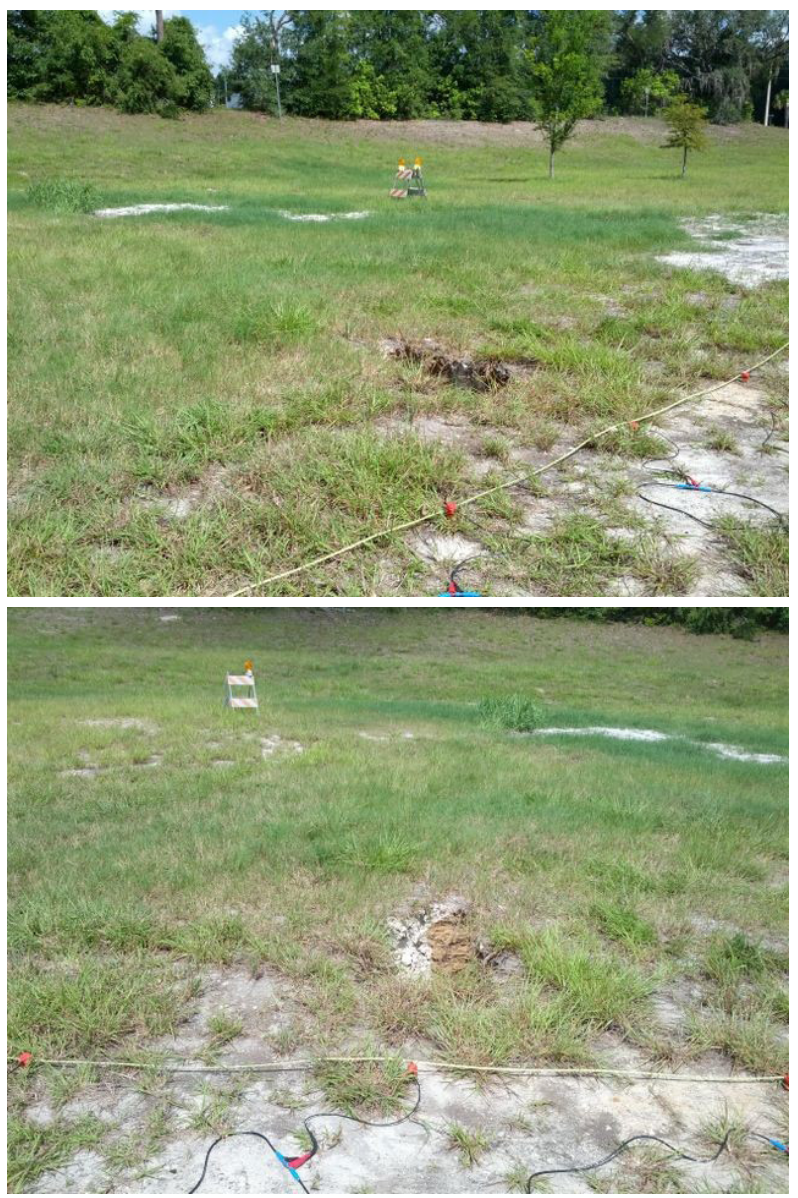

Figure 1. Southern portion. Clockwise from upper left: (A) Test location diagram; (B) Chimney 1 photo; (C) Chimney 2 photo; (D) Chimney 3 photo.

of 10, 15, and $20 \mathrm{~Hz}$; and the final results for data at 20 $\mathrm{Hz}$ are shown in Figure 2B. Locations of chimneys 2 and 3 are also shown in Figure 2B for comparison. The final inverted S-wave profile (Figure 2B, top) shows a lowvelocity zone at distance $20 \mathrm{~m}$ near chimney 2 , along with high lateral and vertical variations in limestone boundaries ( $\mathrm{S}>800 \mathrm{~m} / \mathrm{s}$ ) at the bottom of profile. A valley of lowvelocity area was found at distance $8 \mathrm{~m}$ near chimney 3 . The inverted P-wave profile (Figure 2B, bottom) was consistent with the estimated $\mathrm{S}$-wave profile.

For further verification of the inverted profiles, S-wave velocity profiles from two different perpendicular lines that intersected are shown in Figure 3. The intersection was at distance $22 \mathrm{~m}$ of line 1 and distance $18 \mathrm{~m}$ of line 2. The similarity of two independent S-wave profiles suggested consistency and credibility of the FWI. 

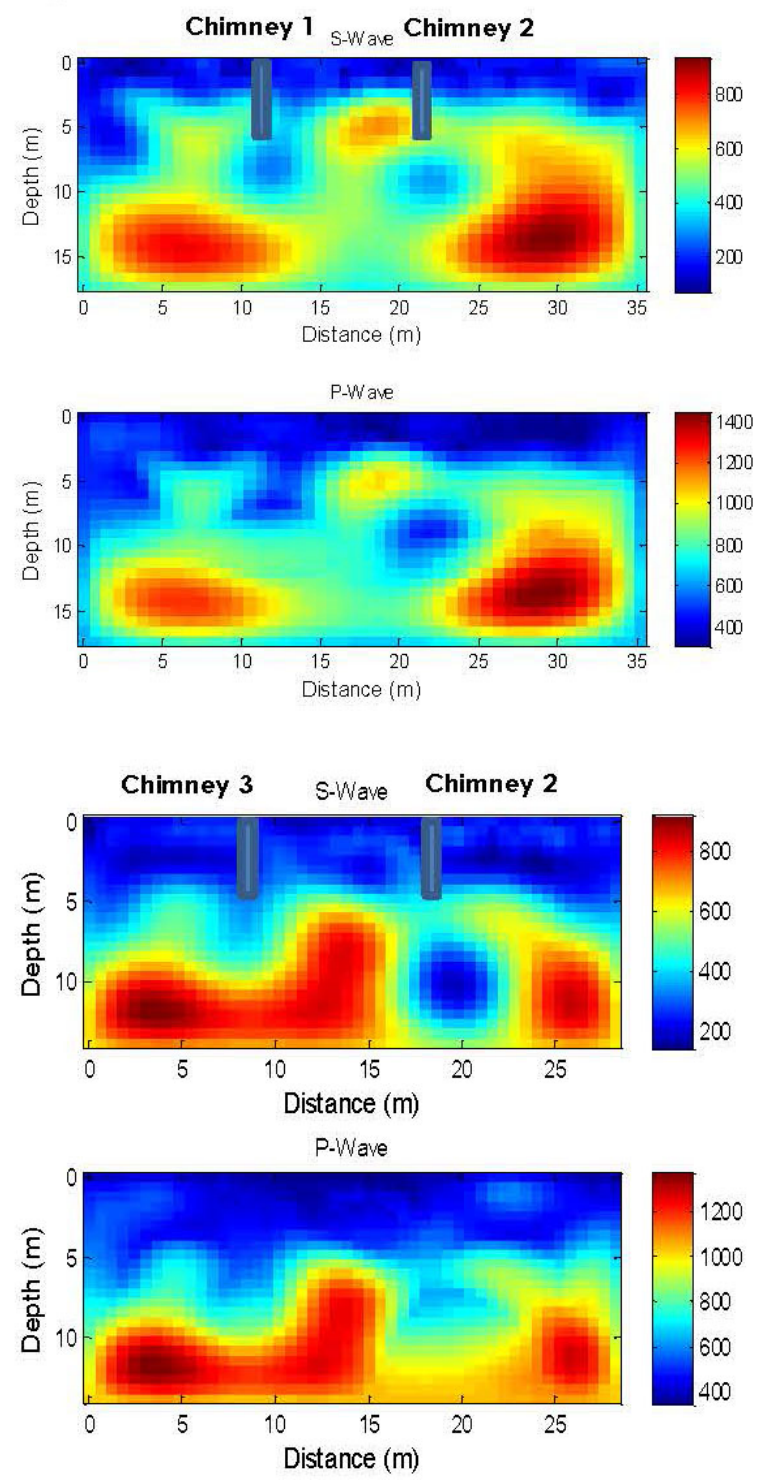

Figure 2. Southern portion: S-wave and $P$-wave velocities ( $\mathrm{m} / \mathrm{s}$ ) of (A, top) Line 1 and (B, bottom) Line 2.

\section{Northern Portion of the Site}

As the northern portion of the site was an open and flat area with no indication of a void on the ground surface, ten test lines were conducted along lines $\mathrm{K}$ through T. Each line was conducted using a linear array of 24 $4.5-\mathrm{Hz}$ vertical geophones at a spacing of $1.5 \mathrm{~m}$, for a total receiver spread of $34.5 \mathrm{~m}$ (station $0.75 \mathrm{~m}$ to 35.25 $\mathrm{m})$. Twenty five shots at $1.5 \mathrm{~m}$ spacing were recorded, for a total shot spread of $36.0 \mathrm{~m}$ (station $0.0 \mathrm{~m}$ to 36.0 $\mathrm{m})$. Acquired seismic data from all ten test lines were analyzed and results from one of them (line Q) with an embedded void are presented here.

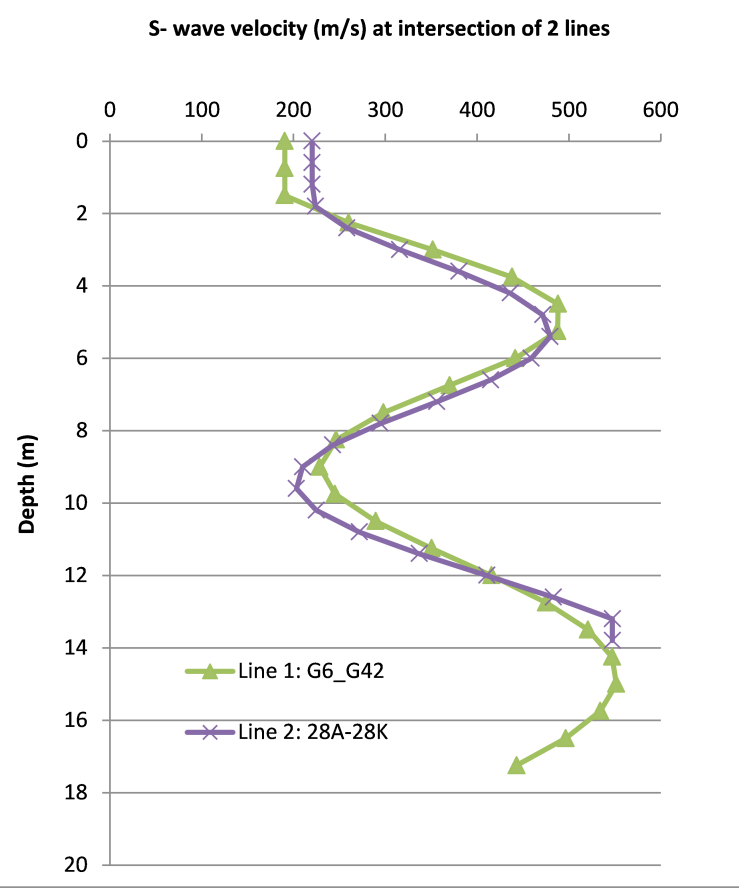

Figure 3. Comparison of inverted S-wave velocity at the intersection of two lines (distance $22 \mathrm{~m}$ of line 1 and distance $18 \mathrm{~m}$ of line 2).

Four inversion runs were conducted for frequency ranges with central frequencies of $6,10,15$, and 20 $\mathrm{Hz}$, beginning from the lowest frequency range. The medium was divided into cells of $0.75 \mathrm{~m} \times 0.75 \mathrm{~m}$. During inversion, S-wave and P-wave velocities of cells were updated independently, and each run was stopped after 20 iterations. The final inversion results at $20 \mathrm{~Hz}$ are shown in Figure 4. The final inverted S-wave profile (top) shows a void embedded at about 6 to $9 \mathrm{~m}$ depth (S-wave velocity less than $50 \mathrm{~m} / \mathrm{s}$ ), along with high lateral and vertical variations in weathered limestone (S-wave velocity more than $600 \mathrm{~m} / \mathrm{s}$ ) boundaries at the bottom of profile.

The inverted P-wave profile (bottom) is consistent with the S-wave profile. To verify the seismic test results, a Standard Penetration Test (SPT) was conducted at the predicted void location (distance $18 \mathrm{~m}$ ) by the sponsor (FDOT) three weeks after the seismic test, and the SPT ' $\mathrm{N}$ ' values are shown in Figure 4B. It is interesting that a void exists at this location that was embedded at about 4 to $7 \mathrm{~m}$ depth, as the SPT 'N' values are zeros (void filled by air) or very low (void filled by raveled soil). Although the 2-D FWI showed the useful capability to locate the void, the predicted depth (6 to $9 \mathrm{~m}$ ) is deeper than the 
real depth of the void (4 to $7 \mathrm{~m}$ ), this is mostly attributed to the discrepancy between the estimated waveform data (plane strain) and the measured data (non-plane strain). Non -plane strain measured data is due to the 3-D void and applied point loads (hammer strikes).

\section{Conclusions}

An application of Gauss-Newton inversion of full seismic elastic waveforms is presented for a highly
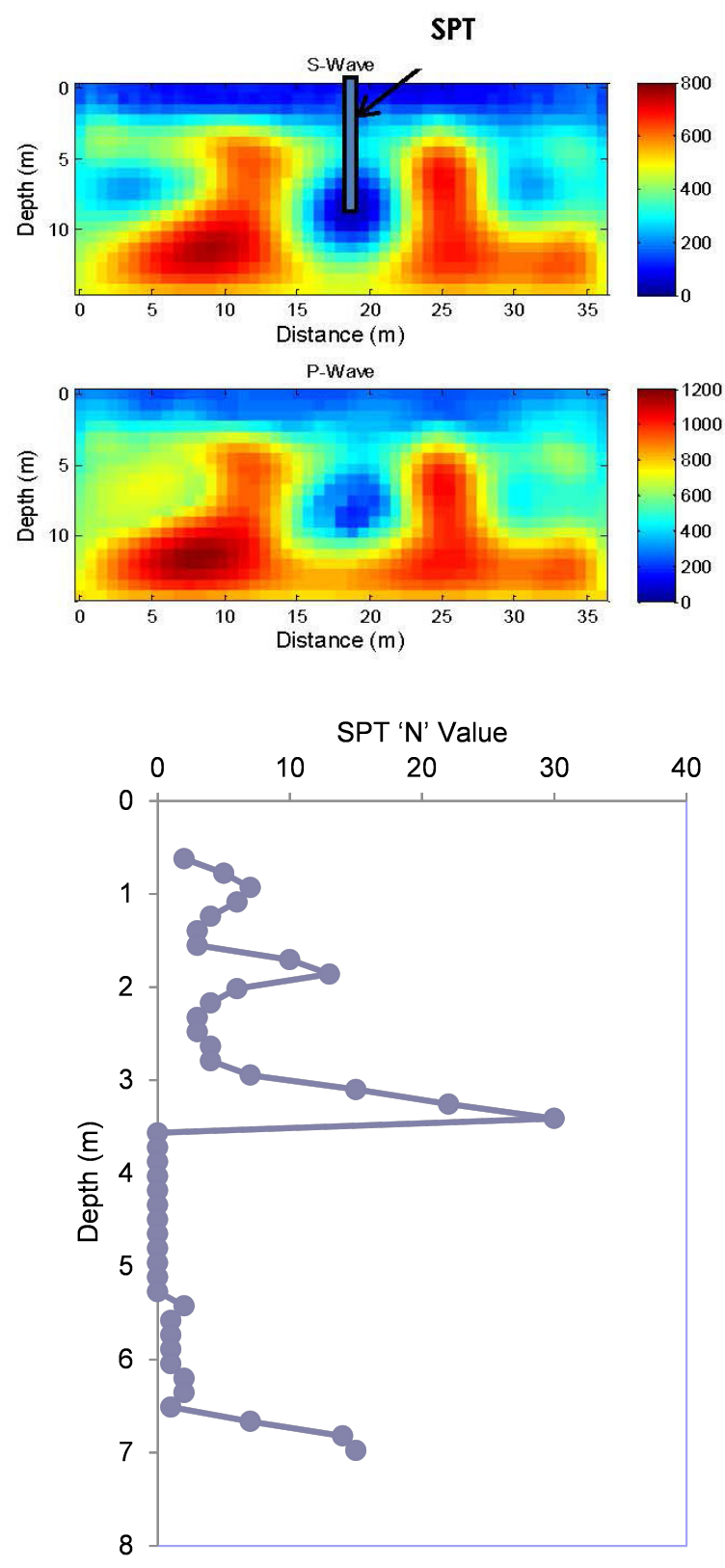

Figure 4. Northern portion: (A, top) S-wave and $P$-wave velocities $(\mathrm{m} / \mathrm{s})$ and $(B$, bottom) SPT ' $N$ ' value. variable (horizontal and vertical) site. The full waveform inversion successfully identified complex subsurface profiles including low-velocity embedded zones, a void, and highly variable limestone surfaces at the bottom of profiles. The inverted results are consistently identified known open karst chimneys in the unconsolidated sediments observed from the ground surface. The independent inverted S-wave velocity profiles at the intersection of two perpendicular test lines are similar, suggesting consistency and credibility of the full waveform inversion technique. The identified void was confirmed by an independent standard penetration test (SPT). For the cases presented, full waveform inversion is computationally practical, as the results obtained were all achieved in about three hours of computer time on a standard laptop computer.

\section{References}

Brenders AJ, Pratt RG. 2007. Full waveform tomography for lithospheric imaging: Results from a blind test in a realistic crustal model. Geophysical Journal International 168 (1): 133-151.

Bretaudeau F, Brossier R, Leparoux D, Abraham O, Virieux J. 2013. 2D elastic full-waveform imaging of the near-surface: application to synthetic and physical modelling data sets. Near Surface Geophysics 11: 307-316.

Cheong S, Pyun S, Shin C. 2006. Two efficient steepest-descent algorithms for source signaturefree waveform inversion. Journal of Seismic Exploration 14: 335-348.

Choi Y, Alkhalifah T. 2011. Source-independent timedomain waveform inversion using convolved wavefields: Application to the encoded multisource waveform inversion. Geophysics 76 (5): R125-R134.

Ge'lis C, Virieux J, Grandjean G. 2007. Two-dimensional elastic waveform inversion using Born and Rytov formulations in the frequency domain. Geophysical Journal International 168: 605-633.

Kamatitsch D, Martin R. 2007. An unsplit convolutional perfectly matched layer improved at grazing incidence for the seismic wave equation. Geophysics 72 (5): SM155-SM167.

Nasseri-Moghaddama A, Cascante G, Phillips C, Hutchinson DJ. 2007. Effects of underground cavities on Rayleigh waves-Field and numerical experiments. Soil Dynamics and Earthquake Engineering 27: 300-313.

Plessix RE. 2008. Introduction: Towards a full waveform inversion. Geophysical Prospecting 56: 761-763. 
Ravaut C, Operto S, Improta L, Virieux J, Herrero A, Dell'Aversana P. 2004. Multiscale imaging of complex structures from multifold wide-aperture seismic data by frequency-domain full-wavefield tomography: Application to a thrust belt. Geophysical Journal International 159: 1032-1056.

Romdhane A, Grandjean G, Brossier R, Rejiba F, Operto S, Virieux J. 2011. Shallow-structure characterization by 2D elastic full-waveform inversion. Geophysics 76 (3): R81-R93.

Sheen DH, Tuncay K, Baag CE, Ortoleva PJ. 2006. Time domain Gauss-Newton seismic waveform inversion in elastic media. Geophysical Journal International 167: 1373-1384.

Shipp RM, Singh SC. 2002. Two-dimensional full wavefield inversion of wide-aperture marine seismic streamer data. Geophysical Journal International 151: 325-344.

Tran KT, Hiltunen DR. 2011. Inversion of FirstArrival Time Using Simulated Annealing. Journal of Environmental and Engineering Geophysics 16: 25-35.

Tran KT, McVay M. 2012. Site Characterization Using Gauss-Newton Inversion of 2-D Full Seismic Waveform in Time Domain. Soil Dynamics and Earthquake Engineering 43: 16-24.

Virieux J. 1986. P-SV wave propagation in heterogeneous media: velocity-stress finitedifference method. Geophysics 51 (4): 889-901.

Virieux J, Operto S. 2009. An overview of fullwaveform inversion in exploration geophysics. Geophysics 74 (6): WCC1-WCC26. 